\title{
Analysis of Operating Mechanism and Implementation of Engineering Quality Insurance System
}

\author{
Duo Zhao \\ Tianjin University of Technology, Tianjin 300384, China \\ Duoduoerzhao@163.com
}

\begin{abstract}
Keywords: Inherent Defect Insurance; Mechanism Analysis; Implement Obstacles; Insurance Products
\end{abstract}

\begin{abstract}
The application and development of the engineering quality insurance system in other countries have shown that it has played an important role in ensuring the quality of construction projects. This paper intends to analyze the existing problems of China's engineering quality insurance system from the aspect of implementation and operation and put forward corresponding countermeasures. Firstly, it analyzes the mechanism of Shanghai Pilot Project Quality Insurance System, and then explores the barriers to the implementation of China's Project Quality Insurance System. Then, some countermeasures to deal with obstacles to implementation are put forward in terms of optimizing product design, encouraging project participants and training insurance professionals and fostering risk management institutions so as to promote the development of China's engineering quality insurance system.
\end{abstract}

\section{Introduction}

Project quality has always been a high concern for the construction industry. Our government departments have taken a series of policies and measures to supervise and guarantee the quality of the projects. However, during the use of the project quality complaints have still occurred frequently [1]. Can be seen, the quality of the project has still been a key issues that the construction industry in China faced. Compared with our country take the administrative measures of project quality, the international community used project quality insurance system more widely, through the market means to achieve the quality control and protection of the project. The project quality insurance system originated in France [2], also known as the Inherent Defect Insurance (IDI).

In 2006, Shanghai, Qingdao, Dalian and other 14 cities have conducted pilot work [3]. In the pilot cities above, various departments of the Shanghai government actively cooperated with insurance companies and CIRC to undertake pilot projects of "three-risk and one-in-one" mode for all risks of construction and installation, personal injury insurance and project quality warranty insurance [4]. In 2012, it signed the engineering quality insurance policy for the first time successfully, and then conducted pilot projects in a number of major construction projects in Pudong New Area, Expo Engineering and Rail Transit. However, in general, our engineering quality insurance system is practicing at a slow pace and there are still obstacles in its full implementation. In February 2016, the State Council issued Several Opinions on Further Strengthening the Management of Urban Planning and Construction, put the establishment and implementation of the project quality insurance system on the agenda again. And clarifying the will and determination of the Chinese government in implementing the project quality insurance system [5]. In June of the same year, Shanghai made a positive response and released the Opinions on Implementation of Potential Defects in Commercial Housing and Guaranteed Housing Project Quality Insurance (Shanghai Office [2016] No. 50).

In the academic circles, most of the early researches on engineering quality insurance mainly discussed the importance of implementing the system. In recent years, more studies focused on the engineering quality insurance model in our country and analyzed the obstacles existing in the implementation of our country, but the reasons for the poor performance of pilot projects from the point of view of operation mechanism are relatively weak. To analyze the project quality insurance system in Shanghai which is relatively mature in our country, we can make clear the obstacles existing 
in the implementation of the project quality insurance system in our country. From the perspectives of the project participants, the design of insurance products and the risk management institutions, we put forward some countermeasures to promote and perfect the pilot projects.

\section{Operating Mechanism Analysis and Existing Obstacles of Shanghai Pilot Project Quality Insurance System}

\subsection{Participant Analysis and Problems}

Participants in the Shanghai Pilot Project Quality Insurance System (hereinafter referred to as "Shanghai Model") include co-insured entities and co-body protection, and implemented them in accordance with the principle of "co-insuring, jointly guaranteeing, jointly controlling and checking each other". Co-insured entities insured by the survey, design, construction and other enterprises, cobody protection includes the insurance companies and risk management agency. The risk management agency mentioned in the Shanghai model is essentially the same body as the quality inspection agency under the French Inherent Defect Insurance System. They are responsible for conducting checks and conducting risk management at all stages of the construction project.

\subsubsection{Problems of Co-insurance Entities}

\section{Lack of insurance awareness}

China's project quality insurance is non-compulsory insurance, voluntarily insured by the project participants. As the insurance industry started relatively late in our country, the overall insurance awareness is relatively weak, especially in the field of construction projects. The participants in the project generally lack incentives to insure themselves.

\subsubsection{Problems of Co-body Protection}

1. Insurers lack specialized personnel

Engineering quality insurance system involves engineering, economy, insurance, law and many other areas of cross-cutting, which requires project insurance companies and risk management agency should have a higher relevant professional staff. However, in our country's insurance market, there is a lack of compound talents who have the insurance knowledge and engineering knowledge [6]. The training of such talents has become an urgent problem to be solved.

2. The risk management institution is underdeveloped and its positioning is not clear

Risk management agency plays an important third-party role in the engineering quality insurance system supervises the whole process of underwriting projects and provides strong technical support. However, the risk management institution in our country is still in its infancy, and the overall market is immature. The management experience of its project quality risks needs to be improved [7]. In addition, due to the different responsibilities and work contents of the risk management institutions and supervision units, completely replacing the supervision agencies may lead to new quality risks.

\subsection{Product Design Analysis and Problems}

\subsubsection{High Rates and Premiums are Not Accurate}

China's benchmark rate is generally $1.5 \%$, at the same time according to market needs to take the floating rate of $4 \%-6 \%$, the whole appears higher than the French internal defect insurance system $3 \%$ fixed rate. The determination of insurance premium rate is mainly based on the evaluation report obtained by the risk management institution on the risk assessment of the common insurance entities and construction projects before the start of construction. Since China has not yet established a comprehensive and systematic risk assessment mechanism, it relies solely on the risk management agency. As a result, the accuracy of setting premiums is largely controlled by the professional standards of the risk management agency.

\subsubsection{Definition of Quality Responsibility is Not Clear}

The laws and regulations system of China's engineering quality insurance system is still not perfect, the definition of quality responsibility nor detailed division and description [8]. The existing regulations only stipulate the minimum warranty period for the main structure of the construction project and the decoration project. The responsibilities for the main body of responsibility are not classified according to different structural positions, different equipments and different performances. 
Correspondingly, the definition of quality responsibility in project quality insurance system is also rather vague [9].

\subsection{Operating Procedures Analysis and Problems}

When a quality defect occurs, the operating procedure of the Shanghai Pilot Insurance System is shown in Figure 1. The owner submits a claim to the insurance company. The insurance company must make the verification within 7 days. If the situation is complicated, the insurance company should make the verification within 30 days and notify the owner of the result. If within the scope of insurance coverage, the insurance company in the compensation agreement reached with the insured within 7 days to fulfill the obligation of compensation; if not covered by the insurance coverage, the insurance company gives the landlord a notice and explains why it is not compensable within 3 days from the date of approval. If the owners disagree with the result of the verification, they may jointly entrust other appraisal agencies with the insurance company to conduct the appraisal again.



Figure 1 Shanghai Pilot Insurance Operation Procedures

Due to the absence of a liability insurance policy in the Shanghai model, the insurer cannot recover the subrogation of the construction entities, design units and other participating entities after the occurrence of the claim, thus aggravating the burden on the insurance companies.

\section{The Implementation of Engineering Quality Insurance System Countermeasures}

\subsection{Optimization of Insurance Product Design}

\subsubsection{Optimize Premiums and Rates}

The design of insurance products emphasizes pertinence and maneuverability, as is engineering quality insurance. In terms of determining premiums, release Shanghai bundled mode of "Three Hazards and Oneness". It will reduce the embarrassment of not being able to establish insurance premiums because one responsible party is unwilling to sign an insurance contract. The premium rates should be gradually implemented different rates, according to the level of regional economic development and the basic situation of each item to determine premium rates.

\subsubsection{Clearly Define the Quality of Responsibility}

The quality liability of engineering quality insurance products in our country only stipulates the minimum life, and draws lessons from the relevant rules of quality liability in the inherent defect insurance system of France. And we can carry out the limitation of years according to the different projects and the corresponding performance, and then make a clear definition about responsibilities of the main responsibility.

\subsection{Incentive Direct Participants}

\subsubsection{Strengthen Publicity to Encourage Insurance Coverage}

The risk awareness and insurance awareness of the project participants are one of the main factors restricting the implementation of the project quality insurance system. The government departments should increase the publicity and promotion of the project quality insurance system to help insurance companies to open the market and enhance the project participants' understanding of the quality insurance system, to enhance their enthusiasm for insurance.

\subsubsection{Conduct Credit Rating on the Direct Participants of the Project}

Government departments can encourage project participants to insure project quality insurance by formulating credit evaluation measures. According to the qualification level of each participating party, the degree of completion of the project and the completion of the project after the complaint status scoring evaluation, and then credit evaluation. 


\subsection{Train Insurance Professionals and Develop Risk Management Organizations \\ 3.3.1 Training Professionals}

In order to expand the engineering quality insurance business, the insurance company should strengthen the construction of specialized employment team and cultivate talents in project quality insurance actuarial, underwriting, reimbursement and professional sales.

\subsubsection{Foster Risk Management Institutions}

The establishment of a risk management institution shall be supported by the national policies and the relevant departments of the government shall set up systems, personnel and functions so as to speed up the development of risk management institutions. In addition, the operation of risk management agency needs to be coordinated with the project supervision system to avoid duplication, cross-cutting and confusion between the two. The supervision units entrusted by the construction unit at this stage focus on the work of " Three control, two tubes, a coordination " during the construction of the project, while the risk management agency conduct risk control and risk assessment throughout the project construction. With the continuous development of project quality insurance system in the future, the supervisory unit and the risk management institution can be hired uniformly by insurance companies to make a clear and reasonable division of the functions of both parties.

\section{Conclusion}

Effective implementation of engineering quality insurance system is one of the important ways to improve the quality of our country's engineering. Based on the analysis of the mechanism of engineering quality insurance system, this paper summarizes the obstacles existing in the implementation of engineering quality insurance system in our country and puts forward suggestions from three aspects. First, it simplifies the design of insurance products. Second, it encourages the active participation of project participants Third, insurance professionals and nurture risk management agency. Through joint efforts of all participants, the effective operation and promotion of China's engineering quality assurance insurance can be implemented as soon as possible so as to further ensure the quality of construction projects and safeguard the rights and interests of the vast number of property owners.

\section{References}

[1]. Yang Yan and Lu Yan. Positioning Analysis and System Suggestion of Government Supervision Function of Residential Quality [J] .Journal of Project Management, 2013 (1): 14-18.

[2]. Hu Yali, Xia Nan, Lu Yan. Research on Implementation Plan of Residential Project Quality Insurance in China [J] synthesis, 2012, 26 (3): 37-40.

[3]. Wang Yun. Research on Engineering Quality Risk Management Model under Potential Defective Engineering Quality Insurance System [J] .Shanghai Insurance, 2017, (06): 17-21.

[4]. Zhao Zhenyu, Ling Wenjun. Comparative analysis and countermeasures of quality insurance system of Chinese and foreign construction [J] .Business Economy, 2010, (08): 5-8.

[5]. Yang Jin. Optimization of construction quality insurance mode [J]. Construction Supervision, Inspection and Costs, 2017, 10 (04): 32-34.

[6]. Guo Zhenhua, Dai Jianlin. Optimum Choice of Engineering Quality Insurance System in China [J] .Business Economics, 2011 (3): 5-10.

[7]. Zhang Xiekui, Peng Yihui, Yang Guandi, et al. Existing problems and countermeasures of construction quality insurance in China [J] .Business Economy, 2016, 37 (1): 16-20

[8]. Xu Youquan, Zhang Shiyang. Construction of China's Construction Quality Liability Insurance Operation Mechanism [J]. China Civil Engineering and Management Journal, 2013, 30 (4): 6872. 
[9]. Zhang Shilian, Ma Ting, Wang Feng. Construction of China's Residential Quality Assurance Insurance System [J]. China Civil Engineering Journal, 2007, (01): 85-89. 